\title{
Clinical and economic impact of pharmacist interventions on sampled outpatient prescriptions in a Chinese teaching hospital
}

\author{
Zhiwei Bao', Chunmei $\mathrm{Ji}^{2}$, Jing $\mathrm{Hu}^{2}$, Can Luo ${ }^{2^{*}+}$ and Wentong Fang ${ }^{2^{*+}}$ (D)
}

\begin{abstract}
Background: Limited studies have evaluated the effectiveness of pharmacist interventions on outpatient prescription. The goal of this study was to evaluate the clinical and economic impacts of pharmacist interventions on randomly sampled outpatient prescriptions.
\end{abstract}

Method: Outpatient prescriptions of our hospital were sampled automatically and reviewed by pharmacists since 2011. Pharmacists intervened in inappropriate prescriptions (IPs) real-timely, and summarized and analyzed the information monthly. Cost-benefit analysis was performed to estimate the economic benefit of the pharmacist intervention.

Results: From 2011 to 2016, pharmacists reviewed 101,271 prescriptions and intervened in 5155 prescriptions. With the interventions of pharmacists, the number of IPs decreased from 1845 to 238, while the inappropriate percentage decreased from 12.60 to $1.22 \%$. The inappropriate rates of different departments and the types decreased annually. IPs were mainly from the Department of Medicine and Department of Surgery and category 1 (Non-indicated medications) in all years. The benefit-to-cost ratios of pharmacist interventions were always more than 1. In the same years, the benefit-to-cost ratios in public payments were higher than those with insurance and self-payment.

Conclusion: This form of pharmacist intervention constitutes a method that showed positive clinical and economic benefits and is worth expanding in large hospitals. Pharmacists should pay more attention on prescriptions in department of surgery or prescriptions with public payments.

Keywords: Pharmacist intervention, Outpatient prescription, Cost-benefit analysis, Experimental research, Economic evaluation, Drug errors

\section{Background}

Used appropriately, medications can alleviate distressing symptoms that compromise physical and psychological well-being, help to prevent the onset of many acute and chronic illnesses, and improve patient health outcomes. Too often, however, medications are not used appropriately [1]. In addition to problems involving adverse drug events (ADEs), many patients do not receive optimal pharmaceutical prescriptions. Prescriptions should be

\footnotetext{
* Correspondence: luocan@jsph.org.cn; fangwentong@jsph.org.cn

${ }^{+}$Can Luo and Wentong Fang contributed equally to this work.

2Department of Pharmacy, First Affiliated Hospital of Nanjing Medical

University, No 300 Guangzhou Road, Nanjing City, Jiangsu Province 210029,

People's Republic of China

Full list of author information is available at the end of the article
}

reviewed by pharmacists before the medication is administered to the patient in some medical administrative systems, such as the Joint Commission International (JCI) Accreditation Standards for Hospitals [2].

Prescription reviewing is only one aspect of pharmacist intervention. Over the past five decades, pharmacists have attempted to extend their scope of activity beyond the traditional distributive and dispensing roles $[3,4]$. Pharmacists will generally intervene in cases of medication problems inclusive of all definitions [5]. Pharmacist interventions were reported to help optimize the process of care by improving the quality of the medication use process and disease management through effective interactions with both patients and other health professionals

(c) The Author(s). 2018 Open Access This article is distributed under the terms of the Creative Commons Attribution 4.0 International License (http://creativecommons.org/licenses/by/4.0/), which permits unrestricted use, distribution, and reproduction in any medium, provided you give appropriate credit to the original author(s) and the source, provide a link to the Creative Commons license, and indicate if changes were made. The Creative Commons Public Domain Dedication waiver (http://creativecommons.org/publicdomain/zero/1.0/) applies to the data made available in this article, unless otherwise stated. 
$[6,7]$. However, most of these studies were conducted among inpatient prescriptions.

Pharmacist interventions on outpatient prescriptions were rarely reported. Limited studies were restricted to certain type of outpatient prescriptions, such as prescriptions of pediatric patients [8], geriatric patients [9], emergency patients [10], patients undergoing oral chemotherapy [11, 12] and those with heart failure [13]. These limited articles have all demonstrated that pharmacist intervention can reduce suboptimal prescriptions. However, the effectiveness of pharmacist interventions in overall outpatient prescriptions has not been reported.

One of the best options for outpatient prescriptions intervention is that clinical pharmacists real-timely monitoring all prescriptions and intervening in inappropriate prescriptions (IPs) [14-16]. However, this procedure will not work in China. In our hospital, for example, there are more than 10,000 outpatient prescriptions per day, and each prescription takes a pharmacist 2-3 min to review. If a pharmacist worked $8 \mathrm{~h}$ per day, at least 42-63 pharmacists would be needed to review all outpatient prescriptions. Unfortunately, our hospital cannot afford to employ so many pharmacists, and almost none of the hospitals in China can afford to employ the number of pharmacists they would need.

Another method was proposed by the National Health and Family Planning Commission (NHFPC) of the People's Republic of China in 2010 [17] and has been implemented in more than 100 hospitals since 2011. A certain percentage of prescriptions (more than 1\%o of outpatient prescriptions or more than $1 \%$ of inpatient prescriptions) should be sampled randomly and reviewed by pharmacists [17]. Pharmacists collect and categorize IPs and report to doctors and the Hospital Pharmaceutical Administration Committee (HPAC) monthly. Our hospital has implemented this method and has supplemented it with pharmacist real-time intervention since 2011. However, the economic benefits of pharmacist interventions on randomly sampled outpatient prescriptions have not been evaluated. Thus, the goal of this study was to evaluate the clinical effect of pharmacist interventions on outpatient prescriptions, and its distinguishing effect on different departments, inappropriate types and insurance types. We further analyzed the benefit-to-cost ratios of these pharmacist interventions, which indicate the economic effect of pharmacist interventions.

\section{Methods}

\section{Study design}

This study was performed in a Chinese teaching hospital according to an order of the NHFPC [17-19]. The period of current study lasted from January 1, 2011, to
December 31, 2016. The outpatient department of this hospital is open 6 days per week and provides services to approximately 10,000 outpatients per day. Outpatient prescriptions were generated via a computerized physician order entry (CPOE) system.

The seventh prescription of every prescriber was automatic sampled by the hospital information system (HIS) every day and sent to the pharmacist workstation. Four experienced pharmacists reviewed these prescriptions. This task was the routine work of the Department of Pharmacy. If a prescription was considered to be potentially IP by pharmacists, the issue was communicated to the prescriber via telephone. If the prescriber accepted the intervention and modified the prescription, the previous prescription was judged as an IP. The information about IPs was recorded on a designated form, based on the standards of the NHFPC [17-19]. The pharmacists completed the forms daily as per the specific categories. All of these jobs took pharmacists four hours per working day. An appointed pharmacist summarized and analyzed the information monthly and sent it to HPAC and the prescribers by office automation system, which required another $16 \mathrm{~h}$ per month. The same appointed pharmacist presented and educated about the IP monthly to the medical staff, which required another $2 \mathrm{~h}$ per month.

\section{Description of inappropriate issues}

With reference to ASHP guidelines on a standardized method for pharmaceutical care [20], inappropriate issues were divided into 13 categories (Table 1).

\section{Cost-benefit analysis}

Cost-benefit analysis was performed to estimate the economic benefits of the pharmacist intervention. Cost was defined as the expenses of pharmacist time [15], which included time for prescription reviewing, intervention, summarizing, analyzing and education. Salary of individual pharmacists is different due to their titles of the professional positions. So we used the average hourly salary of pharmacists, which was calculated based on the annual salary and working hours of a regular pharmacist in our hospital. Other factors such as salary promotion could potentially affect the results. The average hourly salary of a pharmacist was calculated based on the annual salary and working hours of a regular pharmacist in our hospital [15]. Benefit was estimated through cost savings, which was defined as the potentially avoidable cost of inappropriate issues intervened in by pharmacists before the medication was dispensed to the outpatient [15]. Benefit was equal to the sum of the expenses of inappropriate issues. The price of drugs that we used was the price when the prescription was made because it changed three times during our study. All of the costs 
Table 1 Description and categories of inappropriate issues

\begin{tabular}{ll}
\hline Categories & Description \\
\hline Category 1 & Medications with no medical indication \\
Category 2 & Medical conditions for which there is no medication prescribed \\
Category 3 & Medications prescribed inappropriately for a particular medical condition \\
Category 4 & Inappropriate medication dose, dosage form, schedule, route of administration, or method of administration \\
Category 5 & Therapeutic duplication \\
Category 6 & Prescribing of medications to which the patient is allergic \\
Category 7 & Actual and potential clinically significant drug-drug, drug-disease, drug-nutrient, and drug-laboratory test interactions \\
Category 8 & Actual and potential adverse drug events \\
Category 9 & Interference with medical therapy by social or recreational drug use \\
Category 10 & Failure to receive the full benefit of prescribed medication therapy \\
Category 11 & Problems arising from the financial impact of medication therapy on the patient \\
Category 12 & Lack of understanding of the medication therapy by the patient \\
Category 13 & Failure of the patient to adhere to the medication regimen
\end{tabular}

With reference to ASHP guidelines on a standardized method for pharmaceutical care, [20] inappropriate issues were divided into 13 categories

were recorded in RMB and then converted to US dollars [21]. The final values are reported in US dollars. The cost-benefit analysis is expressed as benefit-to-cost ratios, which were calculated by dividing the cost of IPs by the cost of pharmacist time.

\section{Statistical analysis}

Categorical variables are presented as numbers and percentages, and continuous variables are presented as the means and standard deviations $(S D s)$. Continuous variables were tested for normal distribution using the Kolmogorov-Smirnov test and Q-Q plots. Categorical variables were compared using the chi-square test or Fisher's exact test and continuous variables by the independent sample $t$-test or the Mann-Whitney test. A two-tailed $p<0.05$ was considered statistically significant. Analyses were performed with SPSS software, version 21 (IBM Corporation, Armonk, New York, USA).

\section{Results}

General data of the outpatient prescriptions reviewed

The seventh prescription of every prescriber was automatic sampled by the hospital information system (HIS) every day and sent to the pharmacist workstation. Hence, prescriptions from every prescriber in different departments could be sampled. A total of 101,271 outpatient prescriptions were reviewed in this study. The number of reviewed prescriptions increased from 14,646 to 19,567 from 2011to 2016. The percentage of sampling varied from 0.67 to $0.78 \%$. General data of the reviewed prescriptions are shown in Table 2. Approximately one-half of the prescriptions were paid at the patient's own expense. The number of prescriptions paid by medical insurance increased slowly from 2011 to 2015 but remained less than $50 \%$ of the total reviewed prescriptions in 2015.There were no significant changes in age, sex, and expenditure type from 2011 to $2015(P>0.05)$.

Table 2 General data of reviewed prescriptions

\begin{tabular}{|c|c|c|c|c|c|c|c|}
\hline & 2011 & 2012 & 2013 & 2014 & 2015 & 2016 & $P$ value \\
\hline Number of prescriptions & 14,646 & 14,936 & 15,216 & 17,961 & 18,945 & 19,567 & \\
\hline Percentage of sampling & 0.70 & 0.67 & 0.68 & 0.76 & 0.78 & 0.78 & \\
\hline \multicolumn{8}{|c|}{ Gender } \\
\hline Male (N, \%) & $7041(48.08 \%)$ & $7122(47.68 \%)$ & 7152 (47.00\%) & $8513(47.40 \%)$ & $9121(48.14 \%)$ & $9404(48.06 \%)$ & 1.000 \\
\hline Female (N, \%) & 7605 (51.92\%) & $7814(52.32 \%)$ & 8064 (53.00\%) & $9448(52.60 \%)$ & $9824(51.86 \%)$ & $10,163(51.94 \%)$ & \\
\hline Age (Mean $\pm S D$ ) & $52.38 \pm 18.85$ & $52.77 \pm 19.04$ & $53.75 \pm 17.83$ & $52.57 \pm 18.92$ & $53.24 \pm 19.52$ & $52.74 \pm 18.79$ & 0.074 \\
\hline \multicolumn{8}{|c|}{ Expenditure type } \\
\hline Self payment (N, \%) & 7645 (52.20\%) & $7833(52.44 \%)$ & 8004 (52.60\%) & $8950(49.83 \%)$ & 8881 (46.88\%) & 8805 (45.00\%) & 1.000 \\
\hline Public payment (N, \%) & $1498(10.23 \%)$ & $1423(9.53 \%)$ & $1412(9.28 \%)$ & $1363(7.59 \%)$ & $1412(7.45 \%)$ & $1454(7.43 \%)$ & \\
\hline Insurance payment (N, \%) & $5503(37.57 \%)$ & $5680(38.03 \%)$ & $5800(38.12 \%)$ & $7648(42.58 \%)$ & $8652(45.67 \%)$ & $9308(47.57 \%)$ & \\
\hline
\end{tabular}




\section{Pharmacist intervention reduced the inappropriate percentage gradually}

With the intervention of pharmacists, the number and percentage of IPs decreased year by year. The number of IPs decreased from 1845 to 238, while the inappropriate percentage decreased from 12.60 to $1.22 \%$ from 2011 to 2016 (Fig. 1). Pharmacist interventions can optimize outpatient prescriptions gradually and continuously.

\section{Pharmacist intervention reduced IPs in different departments}

With the intervention of pharmacists, the inappropriate number and percentage in different departments were decreased annually from 2011 to 2016 (Fig. 2). The inappropriate number in the Department of Medicine was decreased from 856 to 92, while that in Department of Surgery decreased from 542 to 89. In 2016, the numbers of IPs in other departments were very few. The inappropriate rate in the Department of Surgery was decreased from 16.34 to $1.70 \%$, while that in Department of Psychology decreased from 12.94 to $1.50 \%$. In 2016, the inappropriate rate in the Department of Surgery and Department of Psychology was higher than that of other departments. The inappropriate percentage in the Department of Oncology was lower than in other departments.

\section{Pharmacist intervention reduced IPs in different categories}

With the intervention of pharmacists, numbers and percentages of IPs of different types decreased annually in 2011-2016 (Fig. 3). Category 1 (medications with no medical indication) was always the majority inappropriate type, although its percentage decreased annually from 2011 to 2016. Category 3 (inappropriate choice of medication) was the main type of IP in 2011-2013 but was a minority inappropriate type in 2014-2016. Prescriptions of Category 4 (inappropriate medication use) decreased annually in 2011-2016, but constituted $22.69 \%$ of IPs in 2016. The proportions of Category 5 (therapeutic duplication) were always low. With the intervention of pharmacists, inappropriate prescriptions of Category 2, 6 and 7 disappeared in 2016. Inappropriate prescriptions of Category 8-13 have not been found in 2011-2016.

\section{Pharmacist interventions have positive economic effect}

From 2011 to 2016, the cost, which defined as the expenses of pharmacist time, grew from $\$ 4983.62$ to $\$ 7867.52$. The benefit, which expressed as total cost of all inappropriate issues, decreased from $\$ 43,500.30$ to $\$ 8978.16$. The benefit was always higher than the cost, and the benefit-to-cost ratio was always more than 1 (Table 3). This cost-benefit analysis showed positive economic effect for the pharmacist interventions.

\section{Economic effect differs in different payment types}

The benefit-to-cost ratio was more than 1 in every payment type in 2011-2016. However, the benefit-to-cost ratio with public payments was higher than those with insurance payment and self-payment in the same year (Table 4). In 2016, the benefit-to-cost with public payments was 1.63 , while that that with insurance payment and self-payment was 1.02 and 1.19 .

\section{Discussion}

Our research revealed that pharmacist interventions could significantly reduced the percentage of irrational outpatient prescriptions, and this randomly sampled pharmacist interventions had positive economic benefits. Our research has implications for clinical practice and future research, particularly with respect to the emerging role that pharmacists have played in rational drug use surveillance in outpatients.

Many studies have shown the efficacy of pharmacist intervention in optimizing inpatient prescribing

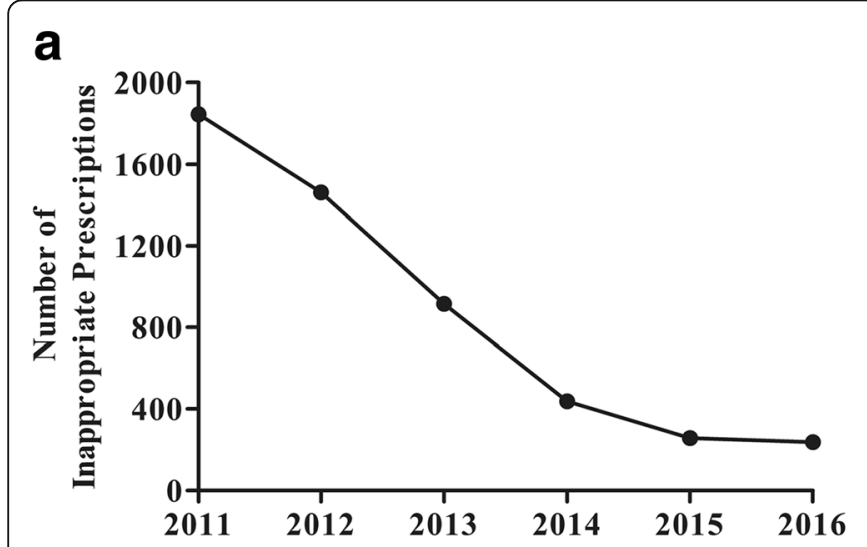

b

Fig. 1 Number (a) and percentage (b) of inappropriate prescriptions in total

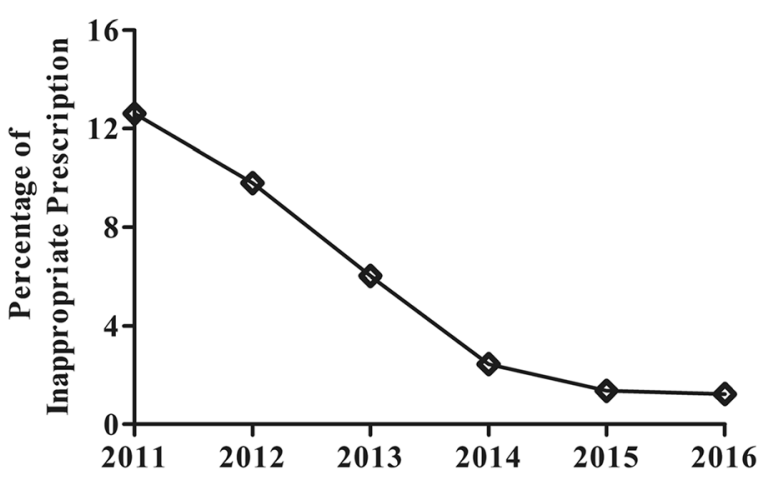



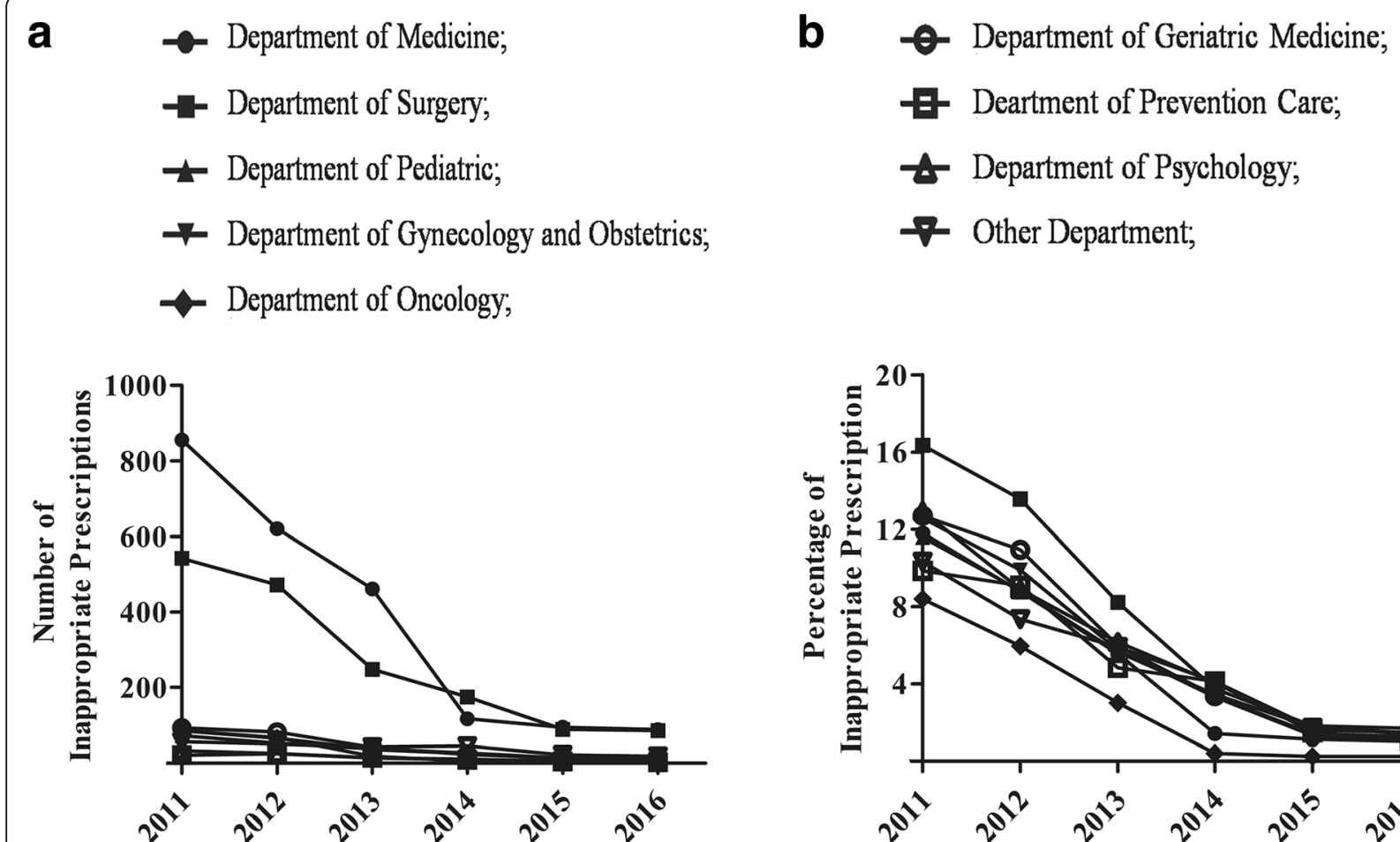

Fig. 2 Numbers (a) and percentages (b) of inappropriate prescriptions in each department

practices [22-25], but few studies have evaluated the issue in outpatients. Therefore, our study focused on the effectiveness of pharmacist intervention in outpatients. Some advantages of outpatient intervention exist in our hospital. First, the number of outpatients in our hospital was large, confirming that we had a sufficient sample size. Second, the doctors in the outpatient department changed little every year in our hospital. Third, self-payment expenditures were paid to the hospital before the medication was dispensed to the patient.
Insurance expenditures and public expenditures were paid by insurance companies and the government on a monthly basis. These advantages made it possible to evaluate the clinical and economic impacts of pharmacist interventions on outpatient prescriptions. In our study, the inappropriate rate of outpatient prescriptions decreased from 12.60 to $1.22 \%$ due to pharmacist interventions from 2011 to 2016 (Fig. 1B). The results agreed with those of previous studies in pediatric outpatients [8], geriatric outpatients [9], emergency outpatients [10],
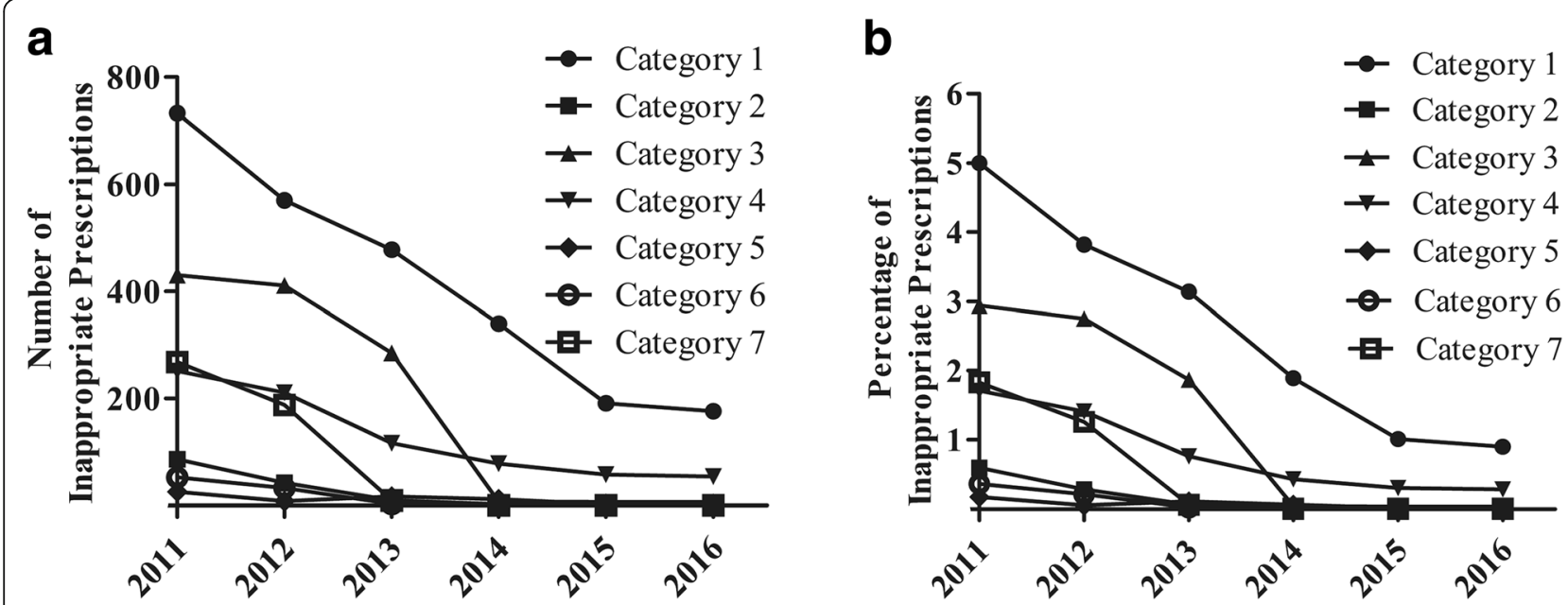

Fig. 3 Number (a) and percentage (b) of each type of inappropriate prescriptions 
Table 3 Cost-benefit analysis of prescription intervention by pharmacists

\begin{tabular}{|c|c|c|c|c|c|c|}
\hline & 2011 & 2012 & 2013 & 2014 & 2015 & 2016 \\
\hline Hourly salary (Dollar) & 4.10 & 4.66 & 5.22 & 5.75 & 6.31 & 6.47 \\
\hline Total pharmacist time (Hour) ${ }^{a}$ & 1216 & 1216 & 1216 & 1216 & 1216 & 1216 \\
\hline Time for reviewing and contacting (Hour) ( $4 \mathrm{~h}$ per working day*250 working days per year) & 1000 & 1000 & 1000 & 1000 & 1000 & 1000 \\
\hline Time for summarizing and analyzing (Hour) ( $16 \mathrm{~h}$ per month *12 months per year) & 192 & 192 & 192 & 192 & 192 & 192 \\
\hline Time for education (Hour) (2 h per month *12 months per year) & 24 & 24 & 24 & 24 & 24 & 24 \\
\hline Total cost of pharmacist time (Dollar) ${ }^{b}$ & 4984 & 5666 & 6352 & 6987 & 7673 & 7868 \\
\hline Total cost of inappropriate prescriptions (Dollar) ${ }^{c}$ & 43,500 & 36,718 & 29,627 & 15,354 & 8723 & 8978 \\
\hline Direct benefit-to-cost ratio ${ }^{d}$ & 8.73 & 6.48 & 4.66 & 2.20 & 1.14 & 1.14 \\
\hline
\end{tabular}

${ }^{\mathrm{a}}$ Total pharmacist time $=($ Time for reviewing and contacting $)+($ Time for summarizing and analyzing $)+($ Time for education $)$;

${ }^{\mathrm{b}}$ Total cost of pharmacist time $=(\text { Total pharmacist time })^{*}$ (Hourly salary);

'Total cost of inappropriate prescriptions = the sum of costs of all inappropriate items;

${ }^{\mathrm{d}}$ Direct benefit-to-cost ratio $=($ Total cost of inappropriate prescriptions $) /($ Total cost of pharmacist time $)$;

outpatients receiving oral chemotherapy $[11,12]$ and those with heart failure [13].

Randomly sampled prescriptions could well represent the overall inappropriate situation for all prescriptions. It has been reported that the irrational incidence of prescriptions or medication orders was estimated to be 1.5915.7\% with physician-pharmacist team work [24, 26-29]. In our study, the inappropriate rate of sampled prescription was $1.22-12.60 \%$ in $2011-2016$ (Fig. 1B).

The effectiveness of randomly sampled pharmacist intervention in our study was not much different from that of overall pharmacist intervention. The recently reported incidence of pharmacist intervention in the CPOE system ranged from 0.5 to $4.8 \%$ [28-31]. Chappuy $\mathrm{M}$ et al... [32] reviewed the outpatient prescriptions of hospital drug sales services in a French university hospital, and 22,279 prescriptions were reviewed over a 1-year period with 247 pharmaceutical interventions (1.1\%). Bedouch P et al [24] reported that the incidence of on-ward pharmacist interventions was $15.7 \%$ with acceptance of $79.2 \%$. Hence, a rate of $3.26 \%$ IPs persisted after the pharmacist intervention. In our study, the inappropriate rate was decreased to as low as $1.22 \%$ over the 6 -year pharmacist intervention (Fig. 1). The randomly sampled pharmacist intervention had similar effect as the fully sampled or on-ward pharmacist intervention.

Though pharmacist intervention could reduce IPs in all departments, it seemed that pharmacist intervention

Table 4 Cost-benefit analysis of pharmacist interventions in different expenditure types

\begin{tabular}{|c|c|c|c|c|c|c|}
\hline & 2011 & 2012 & 2013 & 2014 & 2015 & 2016 \\
\hline \multicolumn{7}{|l|}{ Prescription at self payment } \\
\hline Number of inappropriate prescription & 905 & 720 & 450 & 204 & 116 & 114 \\
\hline Cost of inappropriate prescription(Dollar) ${ }^{a}$ & 20,532 & 17,053 & 14,103 & 6730 & 3844 & 4212 \\
\hline Cost of pharmacist time(Dollar) ${ }^{\mathrm{b}}$ & 2601 & 2971 & 3341 & 3481 & 3596 & 3540 \\
\hline Benefit-to-cost ratio $^{c}$ & 7.89 & 5.74 & 4.22 & 1.93 & 1.07 & 1.19 \\
\hline \multicolumn{7}{|l|}{ Prescription at public payment } \\
\hline Number of inappropriate prescription & 229 & 171 & 107 & 44 & 28 & 27 \\
\hline Cost of inappropriate prescription(Dollar) ${ }^{\mathrm{a}}$ & 6624 & 5701 & 4231 & 2086 & 1001 & 954 \\
\hline Cost of pharmacist time(Dollar) ${ }^{b}$ & 510 & 540 & 589 & 530 & 572 & 585 \\
\hline Benefit-to-cost ratio ${ }^{c}$ & 13.00 & 10.56 & 7.18 & 3.94 & 1.75 & 1.63 \\
\hline \multicolumn{7}{|l|}{ Prescription at insurance payment } \\
\hline Number of inappropriate prescription & 711 & 571 & 359 & 190 & 102 & 97 \\
\hline Cost of inappropriate prescription(Dollar) ${ }^{a}$ & 16,344 & 13,964 & 11,293 & 6538 & 3878 & 3812 \\
\hline Cost of pharmacist time(Dollar) ${ }^{\mathrm{b}}$ & 1873 & 2155 & 2422 & 2976 & 3505 & 3743 \\
\hline Benefit-to-cost ratio $^{c}$ & 8.73 & 6.48 & 4.66 & 2.20 & 1.11 & 1.02 \\
\hline
\end{tabular}

\footnotetext{
${ }^{a}$ Cost of inappropriate prescription in each expenditure type $=$ the sum of costs of inappropriate items of this type;
}

bWe supposed that each prescription took the pharmacist the same time. The time each prescription consumed = (Total pharmacist time)/ (Number of reviewed prescriptions)(see Table 4 and Table 1); Pharmacist time spend on each expenditure type $=($ The time each prescription consumed)* $($ Prescription number of this type)(see Table 1); Cost of pharmacist time $=(\text { Pharmacist time spend on each expenditure type })^{*}$ (Hourly salary) $($ see Table 4$)$;

${ }^{C}$ Benefit-to-cost ratio $=$ (Cost of inappropriate prescription in each expenditure type)/(Total cost of pharmacist time); 
might be most needed in Department of Surgery. The inappropriate percentage in this department was highest in 2011, and reduced significantly by the pharmacist intervention (Fig. 2). However, the inappropriate percentage in this department was still somewhat higher than other department in 2016. The higher inappropriate percentage may because of the low level of standardization of medication use in this department. There are little guidelines or expert consensuses in surgical disease, and guidelines about medication use in Department of Surgery have not issued in our hospital. Pharmacists should pay more attention on rational use of medication in Department of Surgery. The inappropriate percentage in the Department of Oncology was always lower than the other departments (Fig. 2). There are many recognized guidelines in cancer therapy such as National Comprehensive Cancer Network guidelines, ASCO guidelines, ESMO guidelines CSCO guidelines and so on. According to these guidelines in treatment of disease, the pharmacists had issued a guideline for the rational use of anticancer drugs in 2011 in our hospital. This might an explanation of the lower inappropriate percentage in Department of Oncology.

Though pharmacist intervention could reduce IPs in all categories, it seemed that pharmacist intervention might be most needed in Category 1 (medications with no medical indication). Category 1 (medications with no medical indication) was always the majority inappropriate type, although its percentage decreased annually from 2011 to 2015 (Fig. 3). Another Chinese hospital also reported that $48.54 \%$ of urological inpatients undergoing clean or clean-contaminated operations had non-indicated medications before pharmacist interventions [15]. Pharmacists should pay more attention on the irrational issue of medications with no medical indication.

Category 3 (inappropriate choice of medication) decreased rapidly from 2011 to 2016, and became a minority of inappropriate types in 2015. It has reported that most acceptable pharmacist intervention is "inappropriate choices of medications" [24]. As demonstrated by Bedouch P et al. [24], physicians' acceptance of "inappropriate choices of medications" was $84.1 \%$, which was higher than the average level (79.2\%) of pharmacist interventions. This type of irrational issue can improved significantly and quickly by the pharmacist interventions.

Studies of the economic impacts of pharmacist interventions have been limited and have been mostly about inpatients [15, 16, 27, 32-34]. Besides the cost savings, the benefit includes cost avoidance [16] and ultimate improvement. Cost avoidance was defined as the potential economic benefit obtained from interventions that could have prevented ADEs, determined by the total number of intervention cases multiplied by the probability of each potential ADE and the costs associated with ADEs [16]. Ultimate improvement was defined as the practical improvement in health outcome and quality of life. It is very difficult to estimate the cost avoidance and ultimate improvement in outpatients. In our study, benefits included only cost savings, the sum of the expenses for all inappropriate issues. Hence, the benefit of the pharmacist intervention was underestimated in our study.

In our study, the benefit-to-cost ratios of pharmacist interventions were always more than 1 , which showed positive economic effect (Table 3 ). The cost-effective results in our study were not much different from those with reported on-ward pharmacist interventions. Han JM et al....... [16] reported that the cost-benefit ratio was 3.64 with pharmacist interventions for large-volume ambulatory-based chemotherapy. Zhang HX et al [15] reported that the cost-benefit ratio was approximately 18.79 with pharmacist interventions for prophylactic antibiotic use in surgical patients undergoing clean or clean-contaminated operations. Ah YM et al [33] reported that the cost-benefit ratio was 3.8 with pharmacist interventions as members of a liver transplant team for hospitalized liver recipients. Rychlíčková J et al [34] reported that the cost-benefit ratio was 3 with clinical pharmacist interventions in the Czech Republic.

The benefit-cost ratio drops from 8.73 in 2011 to 1.14 in 2016, and it shows the great improvement of reduction of IP mainly due to the interventions and education of pharmacists. For example, if levofloxacin was prescripted for the treatment of mammitis, it was judged as IP by the pharmacist, and the issue was communicated to the prescriber via telephone. In the beginning of next month, educations about antibacterial treatment of mammitis were made to all breast surgeons and gynecologists in order to avoid similar IPs. Intervention and education both played an important role in reducing the number and cost of IPs.

Pharmacist intervention was especially important for prescriptions at public payments. The irrational rates and benefit-to-cost ratios of prescriptions at public payments were highest in our study (Table 4). Prescriptions with public payments are totally paid by the government, and they constitute a large proportion of public health expenditures. Prescriptions with insurance payments are supervised by the insurance companies, while prescriptions with public payments aren't supervised by other organizations. Thus, pharmacist supervision of prescriptions with public payments is especially necessary. There were some limitations of this study. First, this intervention study was performed on the basis of a retrospective design and therefore was less convincing than a prospective, controlled study design. Second, potentially IPs which rejected by doctors were not judged as IPs, which 
could have led to underestimation of the benefit. Third, the favorable results obtained could not be attributed solely to the pharmacist interventions; therefore, a larger sample size and more rigorous design should be employed to evaluate this promising intervention.

The significance of this study lies in the evaluation of interventions performed routinely over a long period of time by pharmacists in a system in which the role of the pharmacist is stable. This system is the basis for expanding the activities of pharmacists, as well as for the possibility of having their work remunerated by the health care insurance system. Despite its limitations, the economic analysis supported these claims.

\section{Conclusion}

The pharmacists persisted in intervening and reducing the inappropriate percentage of outpatient prescriptions in our hospital from 2011 to 2016. This form of pharmacist intervention constitutes a method that showed positive clinical and economic benefits and is worth expanding in large hospitals. Pharmacists should pay more attention on prescriptions in department of surgery or prescriptions with public.

\section{Abbreviations}

ADEs: Adverse drug events; CPOE: Computerized physician order entry; HIS: Hospital information system.; HPAC: Hospital Pharmaceutical Administration Committee; IP: Inappropriate prescription; NHFPC: National Health and Family Planning Commission

\section{Availability of data and material}

The datasets used and/or analyzed during the current study available from the corresponding author on reasonable request.

\section{Funding}

There is no founding for this article.

\section{Authors' contributions}

All authors made substantial contributions to this article. BZ revised this article. FW conducted the study analyzed the data and drafted the manuscript. LC collected the data. JC and HJ participated in the drafting this article. All approved the final manuscript and all agreed to be accountable for all aspects of the work in ensuring that questions related to the accuracy or integrity of any part of the work are appropriately investigated and resolved.

\section{Ethics approval and consent to participate}

Prescription reviewing and intervention was proposed by the NHFPC of the People's Republic of China in 2010. The NHFPC demanded that as many hospitals as possible implement this method. Our hospital implemented this method according to the documents of NHFPC. The ethic committee of our hospital has confirmed that the need for ethical approval is not necessary.

\section{Consent for publication}

Not applicable.

\section{Competing interests}

The authors declare that they have no competing interests.

\section{Publisher's Note}

Springer Nature remains neutral with regard to jurisdictional claims in published maps and institutional affiliations.

\section{Author details}

'Department of Pharmacy, Jiangsu Jianhu People's Hospital, Yancheng 224700, China. ${ }^{2}$ Department of Pharmacy, First Affiliated Hospital of Nanjing Medical University, No 300 Guangzhou Road, Nanjing City, Jiangsu Province 210029, People's Republic of China.

Received: 20 February 2018 Accepted: 18 June 2018

Published online: 04 July 2018

\section{References}

1. Viswanathan M, Kahwati LC, Golin CE, Blalock S, Coker-Schwimmer E, Posey R, Lohr KN. Medication Therapy Management Interventions in Outpatient Settings [Internet]. Rockville (MD): Agency for Healthcare Research and Quality (US); 2014. Report No.: 14(15)-EHC037-EF

2. Joint Commission International. Joint commission international accreditation standards for hospitals. 5th ed; 2014.

3. Rotta I, Salgado TM, Silva ML, Correr CJ, Fernandez-Llimos F. Effectiveness of clinical pharmacy services: an overview of systematic reviews (2000-2010). Int J Clin Pharm. 2015;37(5):687-97. https://doi.org/10.1007/s11096-0150137-9. 26001356

4. Hepler CD. Clinical pharmacy, pharmaceutical care, and the quality of drug therapy. Pharmacotherapy. 2004;24(11):1491-8. https://doi.org/10.1592/phco. 24.16.1491.50950. 15537552

5. Suggett E, Marriott J. Risk factors associated with the requirement for pharmaceutical intervention in the hospital setting: a systematic review of the literature. Drugs Real World Outcomes. 2016;3(3):241-63. https://doi.org/ 10.1007/s40801-016-0083-4. 27747829

6. Carter BL, Rogers M, Daly J, Zheng S, James PA. The potency of team-based care interventions for hypertension: a meta-analysis. Arch Intern Med. 2009; 169(19):1748-55. https://doi.org/10.1001/archinternmed.2009.316. PMID: 19858431.

7. Kaboli PJ, Hoth AB, McClimon BJ, Schnipper JL. Clinical pharmacists and inpatient medical care: a systematic review. Arch Intern Med. 2006;166(9): 955-64. https://doi.org/10.1001/archinte.166.9.955. 16682568

8. Grant JJ, Adams MB, Decker K, McFarland S, Lee CK. Evaluating the impact of a pediatric weight-based dosing procedure in outpatient pharmacy. J Am Pharm Assoc. 2016;56(1):54-7. https://doi.org/10.1016/j.japh.2015.11.004. 26802921

9. Ma JD, Tran V, Chan C, Mitchell WM, Atayee RS. Retrospective analysis of pharmacist interventions in an ambulatory palliative care practice. J Oncol Pharm Pract. 2016:22(6):113-23. https://doi.org/10.1177/1078155215607089. PMID: 26428283

10. Chen M, Zhou Q. Pharmaceutical interventions by collaboration between staff pharmacists and clinical pharmacists and implementation of joint commission international accreditation standards on medication use may optimize pharmacotherapy in geriatric patients. Clin Interv Aging. 2016; 11(11):1575-7. https://doi.org/10.2147/CIA.S123900. 27877026

11. Battis B, Clifford L, Huq M, Pejoro E, Mambourg S. The impacts of a pharmacist-managed outpatient clinic and chemotherapy-directed electronic order sets for monitoring oral chemotherapy. J Oncol Pharm Pract. 2016; Epub 2016 Oct 12; https://doi.org/10.1177/1078155216672314. PMID: 27733666

12. Lam MS, Cheung N. Impact of oncology pharmacist-managed oral anticancer therapy in patients with chronic myelogenous leukemia. J Oncol Pharm Pract. 2016;22(6):741-8. https://doi.org/10.1177/1078155215608523. 26419691

13. Dempsey JT, Matta LS, Carter DM, Stevens CA, Stevenson LW, Desai AS, et al. Assessment of drug therapy-related issues in an outpatient heart failure population and the potential impact of pharmacist-driven intervention. J Pharm Pract. 2017;30(3):318-23. https://doi.org/10.1177/0897190016641491. 27080398

14. Lucca JM, Ramesh M, Narahari GM, Minaz N. Impact of clinical pharmacist interventions on the cost of drug therapy in intensive care units of a tertiary care teaching hospital. J Pharmacol Pharmacother. 2012;3(3):242-7. https:// doi.org/10.4103/0976-500x.99422. 23129959

15. Zhang HX, Li X, Huo HQ, Liang P, Zhang JP, Ge WH. Pharmacist interventions for prophylactic antibiotic use in urological inpatients undergoing clean or clean-contaminated operations in a Chinese hospital. PLoS One. 2014;9(2):e88971. https://doi.org/10.1371/journal.pone.0088971. 24586465 
16. Han JM, Ah YM, Suh SY, Jung SH, Hahn HJ, Im SA, et al. Clinical and economic impact of pharmacists' intervention in a large volume chemotherapy preparation unit. Int J Clin Pharm. 2016;38(5):1124-32. https://doi.org/10.1007/s11096-016-0339-9. 27365091

17. National Health and Family Planning Commission of the People's Republic of China. Hospital prescription review management specification [in Chinese], 2010. Available from http://www.nhfpc.gov.cn/yzygj/s3590/ 201003/ac4d04a85da5478793761224abc1 0fd3.shtml.

18. National Health and Family Planning Commission of the People's Republic of China. Prescription Administrative Policy [in Chinese], 2010. Available from http://www.gov.cn/flfg/2007-03/13/content_549406.htm.

19. National Health and Family Planning Commission of the People's Republic of China. National Special Measure Scheme on Clinical Use of Antibiotics [in Chinese], 2013. Available from http://www.gov.cn/flfg/2012-05/08/content_ 2132174.htm.

20. ASHP guidelines on a standardized method for pharmaceutical care. In: Deffenbaugh J, ed. Best practices for health-system pharmacy. Bethesda, MD: American Society of Health-System Pharmacists, 1996:109-11.

21. The peoples bank of china RMB exchange rate [in Chinese], 2016. Available from http://www.pbc.gov.cn/rmyh/108976/index.html.

22. Riordan DO, Walsh KA, Galvin R, Sinnott C, Kearney PM, Byrne S. The effect of pharmacist-led interventions in optimising prescribing in older adults in primary care: a systematic review. SAGE Open Med. 2016;4:1-18. https://doi. org/10.1177/2050312116652568. 27354917

23. Kajizono M, Aoyagi M, Kitamura Y, Sendo T. Effectiveness of medical supportive team for outpatients treated with sorafenib: a retrospective study. J Pharm Health Care Sci. 2015;1 (1):1-6. https://doi.org/10.1186/ s40780-014-0005-0. PMID: 26819717.

24. Bedouch P, Tessier A, Baudrant M, Labarere J, Foroni L, Calop J, et al. Computerized physician order entry system combined with on-ward pharmacist: analysis of pharmacists' interventions. J Eval Clin Pract. 2012; 18(4):911-8. https://doi.org/10.1111/j.1365-2753.2011.01704.x. 21689216

25. Fernandez-Llamazares CM, Calleja-Hernandez MA, Manrique-Rodriguez S, Perez-Sanz C, Duran-Garcia E, Sanjurjo-Saez M. Impact of clinical pharmacist interventions in reducing paediatric prescribing errors. Arch Dis Child. 2012; 97(6):564-8. https://doi.org/10.1136/archdischild-2011-301239. 22362718

26. Vantard N, Ranchon F, Schwiertz V, Gourc C, Gauthier N, Guedat MG, et al EPICC study: evaluation of pharmaceutical intervention in cancer care. J Clin Pharm Ther. 2015;40(2):196-203. https://doi.org/10.1111/jcpt.12242. 25594148

27. Delpeuch A, Leveque D, Gourieux B, Herbrecht R. Impact of clinical pharmacy services in a hematology/oncology inpatient setting. Anticancer Res. 2015;35(1):457-60. 25550587

28. Le Guen R, Madelaine I, Tournamille JF, Bellanger A, Astier A, Braguer D, et al. Study impacto: descriptive analyzis of pharmacist's clinical practice in onco-hematology. Ann Pharm Fr. 2015;73(3):223-8. https://doi.org/10.1016/j. pharma.2014.10.002. PMID: 25934530.

29. Shulman R, Singer M, Goldstone J, Bellingan G. Medication errors: a prospective cohort study of hand-written and computerised physician order entry in the intensive care unit. Crit Care. 2005;9(5):R516-21. https://doi.org/ 10.1186/cc3793. PMID: 16277713.

30. Nerich V, Limat S, Demarchi M, Borg C, Rohrlich PS, Deconinck E, et al. Computerized physician order entry of injectable antineoplastic drugs: an epidemiologic study of prescribing medication errors. Int J Med Inform. 2010;79(10):699-706. https://doi.org/10.1016/j.jmedinf.2010.07.003. 20829102

31. Suzuki S, Chan A, Nomura H, Johnson PE, Endo K, Saito S. Chemotherapy regimen checks performed by pharmacists contribute to safe administration of chemotherapy. J Oncol Pharm Pract. 2015;23(1):18-25. https://doi.org/10. 1177/1078155215614998. PMID: 26561587.

32. Chappuy M, Garcia S, Uhres AC, Janoly-Dumenil A, Dessault J, Chamouard V, et al. Pharmacist's interventions on outpatient prescriptions in a university hospital drugs sales service. Ann Pharm Fr. 2015;73(4):297-306. https://doi. org/10.1016/j.pharma.2014.11.001. PMID: 25558801.

33. Ah YM, Lee JY, Moon MR, Cho YS, Kim HS, Yi NJ, et al. Clinical and economic evaluation of pharmacists' contribution to patient care on a multi-disciplinary liver transplant team. Int J Clin Pharmacol Ther. 2016;54(2): 102-9. https://doi.org/10.5414/cp202501. 26709599

34. Rychlickova J, Saloun J, Gregorova J. Evaluation of clinical Pharmacists' interventions in the Czech Republic. Pharmacotherapy. 2016;36(7):766-73. https://doi.org/10.1002/phar.1777. 27270831

\section{Ready to submit your research? Choose BMC and benefit from:}

- fast, convenient online submission

- thorough peer review by experienced researchers in your field

- rapid publication on acceptance

- support for research data, including large and complex data types

- gold Open Access which fosters wider collaboration and increased citations

- maximum visibility for your research: over $100 \mathrm{M}$ website views per year

At BMC, research is always in progress.

Learn more biomedcentral.com/submissions 